\title{
OPTIMIZATION OF PACKING DENSITY OF M30 CONCRETE WITH STEEL SLAG AS COARSE AGGREGATE USING FUZZY LOGIC
}

\begin{abstract}
Concrete plays a vital role in the design and construction of the infrastructure. To meet the global demand of concrete in future, it is becoming a challenging task to find suitable alternatives to natural aggregates. Steel slag is a by-product of steel making process. The steel slag aggregates are characterized by studying particle size and shape, physical and chemical properties, and mechanical properties as per IS: 2386-1963. The characterization study reveals the better performance of steel slag aggregate over natural coarse aggregate. M30 grade of concrete is designed and natural coarse aggregate is completely replaced by steel slag aggregate. Packing density of aggregates affects the characteristics of concrete. The present paper proposes a fuzzy system for concrete mix proportioning which increases the packing density. The proposed fuzzy system have four sub fuzzy system to arrive compressive strength, water cement ratio, ideal grading curve and free water content for concrete mix proportioning. The results show, the concrete mix proportion of the given fuzzy model agrees with IS method. The comparison of results shows that both proposed fuzzy system and IS method, there is a remarkable increase in compressive strength and bulk density, with increment in the percentage replacement of steel slag.

Keywords: Steel slag, characterisation,packing density, fuzzy system, compresive strength, bulkdensity
\end{abstract}

\section{Introduction}

Concrete mix design is a procedure to arrive the proportions of the ingredients like, cement, water, coarse aggregate, fine aggregate. To achieve economy in construction, industrial by products are supplemented for the ingredients of concrete. Steel slag is a byproduct of steel making process. Steel slag can be replaced as fine aggregate and coarse aggregate.

Increased percentage of aggregates in concrete inhabits maximum volume and also the higher strength (Neville, 1983). An aggregate with wide range of particles increases the packing density. Therefore, it is beneficial to intensify the particle packing in concrete mix design, which aims to achieve densest mix, minimize the number of voids and increase the aggregate volume without affecting the concrete properties.

Fuzzy logic gives a regular calculus and performs numerical computation accessing linguistic labels stimulated by membership functions. Today fuzzy logic has been used to solve many civil engineering problems.

Previously there are many works are carried out to propose particle packing model for aggregate. This paper aims to access the effect of particle packing using fuzzy logic, in concrete containing steel slag aggregates as coarse aggregate.

\section{Background}

T. Sowmiya (2004) studied the optical basicity of slags and concluded the presence of high $\mathrm{CaO}$ in steel slag by studying the microstructural properties [1].

Y. Kirillidi (2005) suggested that due to its hydraulic properties, in the light concrete for the construction of the base of roads and to produce an anti-slippery blacktop material replacing $100 \%$ the limestone aggregates [2].

Jigar P. Patel (2006) concluded that the compressive strength, flexural strength and split tensile strength for steel slag aggregate concrete were similar to conventional concrete [3]. Mohammed Nadeem (2012), revealed improvement of compressive strength, split tensile and flexure strength over control mixes by 4 to $8 \%$. The replacement of $100 \%$ slag aggregate (coarse) increased concrete density by about 5 to 7\% compared to control mix [4].

I. Netinger (2012) concluded that at higher temperatures, steel slag exhibits mineral transformation followed by unstable volumetric expansion which reflected negatively on the residual properties of slag based concrete mixtures [5].

K.G. Hiraskar (2013) revealed that the compressive strength of Blast Furnace Slag aggregate concrete is found to be higher than that of conventional concrete at the age of 90 days. It has also reduced water absorption and porosity beyond 28 days in comparison to that of conventional concrete with stone chips used as coarse aggregate [6].

\footnotetext{
SONA COLLEGE OF TECHNOLOGY, SALEM-636 005, TAMILNADU, INDIA

\# Corresponding author: arivu_sen@yahoo.com
} 
Dr.K. Chinnaraj (2013) studied that by replacing about 60 percent of steel slag aggregates for coarse aggregate and 40 percent of ecosand for fine aggregate will not have any adverse effect on the strength of the concrete [7].

Sultan A. Tarawneh (2014) by thorough investigation of the results have indicated that the amount of increase in compressive strength at age of 7 days are much more than that of age 28 days for all types of aggregate replacement. This indicates that the added slag could work as accelerator at early age while at 28 days age; the effect is reduced [8].

Khalid Raza (2014) suggested that the use of iron slag in concrete could enhance the strength in concrete [9].

Parviz Ghoddousi1 et.al (2015) reviewed that better packing of aggregates improves the strength, durability, elastic modulus and creep of the concrete. Accordingly, by increasing packing density and decreasing cement content, environment pollution will decrease. The proposed system utilizes four sub-fuzzy systems to quantify the target compressive strength, water-to-cement ratio, ideal grading curve and free water of the concrete [10].

Thomas H. Bleeck (2011)investigated that an effective approach was developed optimize the particle packing of aggregates and powders in the concrete mix design with the aim to increase the aggregate proportions used by minimizing the number of voids and increasing the density of the concrete [11].

\section{Material properties}

\subsection{Cement}

Ordinary Portland cement (Ultratech43 Grade) confirming to IS: 8112-1989 was used throughout the investigation.

\subsection{Sand (Fine Aggregate)}

Locally available river sand passing through $4.75 \mathrm{~mm}$ sieve as per IS: 383-1970 provisions were used as fine aggregates. The physical property of fine aggregate is shown in Table 1.

TABLE 1

Physical Properties of Fine Aggregate

\begin{tabular}{|c|c|}
\hline \hline Description & Fine aggregate \\
\hline Specific gravity & 2.6 \\
\hline Water absorption & $1.57 \%$ \\
\hline Fineness modulus & $3.1($ zone II) \\
\hline Surface moisture & $\mathrm{Nil}$ \\
\hline Bulk density & $1450 \mathrm{~kg} / \mathrm{m}^{3}$ \\
\hline
\end{tabular}

\subsection{Coarse Aggregates [Natural]}

Machine crushed locally available hard granite, well graded $20 \mathrm{~mm}$ and down sized was used for preparation of concrete.

\subsection{Steel Slag}

This slag is a by-product from steelmaking processes in which the components of pig iron and steel-scrap are modified in order to produce steel that is highly valued for excellent toughness and workability. For every ton of steel production, about $200 \mathrm{~kg}$ of slag is generated. In JSW Steel Ltd., Salem Works (JSWS), India, 12000-13000 tons of steel Slag is produced per month and 2, 00,000 $\mathrm{m}^{3}-3,00,000 \mathrm{~m}^{3}$ steel slag is produced annually.

\section{Methods of test for coarse aggregate for concrete}

The characteristics of concrete mainly depend upon the properties of materials used. Grading, mineralogical composition, shape and texture of the aggregate affects the fresh and hardened properties of concrete. Therefore, it is necessary to study the characteristics of materials used in concrete to obtain a good quality concrete. To characterize the steel slag, the following tests were conducted as per Indian Standard (IS: 2386-1963) methods and compared with the properties of natural aggregates.

i. Particle Size and Shape

- Sieve analysis

- Determination of flakiness index

- Determination of elongation index

- Determination of angularity number

ii. Determination of light weight particles

iii. Physical Properties

- Determination of specific gravity and water absorption

- Determination of bulk density

iv. Mechanical Properties

- Determination of Aggregate Crushing value

- Determination of the 10 percent Fines Value

- Determination of Aggregate Impact Value

- Determination of Aggregate Abrasion Value

- Determination of Aggregate Attrition Value

v. Chemical Test

\subsection{Particle size and shape}

The ungraded steel slag obtained from steel industries, is graded and it confirms to IS: 383-1970.

It is seen from the TABLE 2, the flakiness index of steel slag is lower than the natural aggregates which shows that the steel slag particles are thicker than that of the natural coarse aggregate. The elongation index of steel slag is a little higher than that of natural aggregate, it implies slag particles are shorter than natural coarse aggregate.

Angularity or absence of rounding of the particles of an aggregate is a property which is of importance because it effects the ease of handling of a mixture of aggregate and binder, for example the workability of concrete, or the stability of mixtures that rely on the interlocking of the particles. It is observed that 
the angularity number is same for steel slag and natural coarse aggregate from the Table 2.

TABLE 2

Particle Shape Properties of Steel Slag and Natural Coarse Aggregate

\begin{tabular}{|c|c|c|}
\hline \hline Test & Natural Coarse Aggregate & Steel Slag \\
\hline Flakiness index & $22.2 \%$ & $8 \%$ \\
\hline Elongation index & $52.5 \%$ & $41 \%$ \\
\hline Angularity number & 20.83 & 20.41 \\
\hline
\end{tabular}

\subsection{Determination of light weight particles}

As per ASTM C 123 the presence of light weight particles is done. The percentage of light weight particles is $5 \%$ which is very lean to consider.

\subsection{Physical properties}

The Table 3 indicates the water absorption of Steel slag is around $1 \%$ higher than that of natural aggregate which in turn will affect the workability of the concrete. The bulk density result indicates steel sag is heavier than natural coarse aggregate. The specific gravity of steel slag and natural coarse aggregate has very thin difference only.

TABLE 3

Physical Properties of Steel Slag and Natural Coarse Aggregate

\begin{tabular}{|c|c|c|}
\hline Test & Coarse Aggregate & Steel Slag \\
\hline Specific gravity & 2.75 & 2.86 \\
\hline Bulk density & $2886 \mathrm{~kg} / \mathrm{m}^{3}$ & $3020 \mathrm{~kg} / \mathrm{m}^{3}$ \\
\hline Water absorption & $0.8 \%$ & $1.01 \%$ \\
\hline
\end{tabular}

\subsection{Mechanical properties}

The mechanical properties of the aggregates influence the strength of the concrete. For making strong concrete strong aggregates are essential. From the Table 4, it is seen that steel slag produces higher results than natural aggregate for the strength tests like Crushing value, 10 percent Fines Value and Impact Value.

TABLE 4

Mechanical Properties of Steel Slag and Natural Coarse Aggregate

\begin{tabular}{|c|c|c|c|}
\hline \hline Test & $\begin{array}{c}\text { Coarse } \\
\text { Aggregate }\end{array}$ & Steel Slag & $\begin{array}{c}\text { Limiting Value } \\
\text { as per IS }\end{array}$ \\
\hline Crushing Value & $6.55 \%$ & $8 \%$ & Not more than $30 \%$ \\
\hline 10 percent Fines value & $7.8 \%$ & $8.3 \%$ & $7.5 \%$ to $12.5 \%$ \\
\hline Impact value & $22.87 \%$ & $29.57 \%$ & Less than $30 \%$ \\
\hline Los Angele’s Abrasion & $8.27 \%$ & $1.16 \%$ & Not more than $50 \%$ \\
\hline Deval's Attrition & $18.56 \%$ & $3.68 \%$ & - \\
\hline
\end{tabular}

The resistance to wear observed by Los Angeles abrasion and Deval's Attrition shows the good performance of the steel slag than natural coarse aggregate.

\subsection{Chemical test}

The chemical analysis of steel slag indicates the presence of high percentage of $\mathrm{CaO}$ and $\mathrm{FeO}$. Apart from these the steel slag also contains considerable amount of MgO. The chemical analysis of steel slag is provided in the Table 5.

TABLE 5

Chemical Composition of Steel Slag

\begin{tabular}{|c|c|}
\hline \hline Parameter & Steel slag (\%) \\
\hline $\mathrm{CaO}$ & 35.28 \\
\hline $\mathrm{MgO}$ & 9.27 \\
\hline $\mathrm{SiO}_{2}$ & 16.69 \\
\hline $\mathrm{Al}_{2} \mathrm{O}_{3}$ & 6.20 \\
\hline $\mathrm{MnO}$ & 1.88 \\
\hline $\mathrm{FeO}$ & 26.91 \\
\hline $\mathrm{P}_{2} \mathrm{O}_{5} \mathrm{O}$ & 1.43 \\
\hline $\mathrm{Na}_{2} \mathrm{O}$ & 0.16 \\
\hline $\mathrm{K}_{2} \mathrm{O}$ & 0.03 \\
\hline $\mathrm{SO}_{3}$ & 0.56 \\
\hline
\end{tabular}

\section{Mix Design}

The mix design for concrete M30 grade is arrived based on the code IS 10262:2009, and the obtained mix proportion is $1: 1.45: 2.62$ and water cement ratio is 0.45 .

\section{Proposed Fuzzy System}

The proposed fuzzy system for mix design of concrete was shown in Fig. 1. The integrated system is composed of the following sub-fuzzy systems:

- CS system: compressive strength sub-fuzzy system is designed to quantify the target compressive strength.

- W/C system: Water/cement ratio sub-fuzzy system is designed to determine the water-to-cement ratio of required grade of concrete.

- IGC system: Ideal grading curve sub-fuzzy system is designed to estimates the volume of coarse and fine aggregate and draw an ideal grading curve.

- $\quad$ FW system: Free water sub-fuzzy system designed to estimate the available free water of concrete.

Each sub-fuzzy system decomposes the input and output variables by using fuzzy membership functions. Trapezoidal and triangular membership functions are used and the sub-fuzzy system generated, are Mamdani type. The design and implementation of inference system are done in MATLAB software with its fuzzy logic toolbox. 


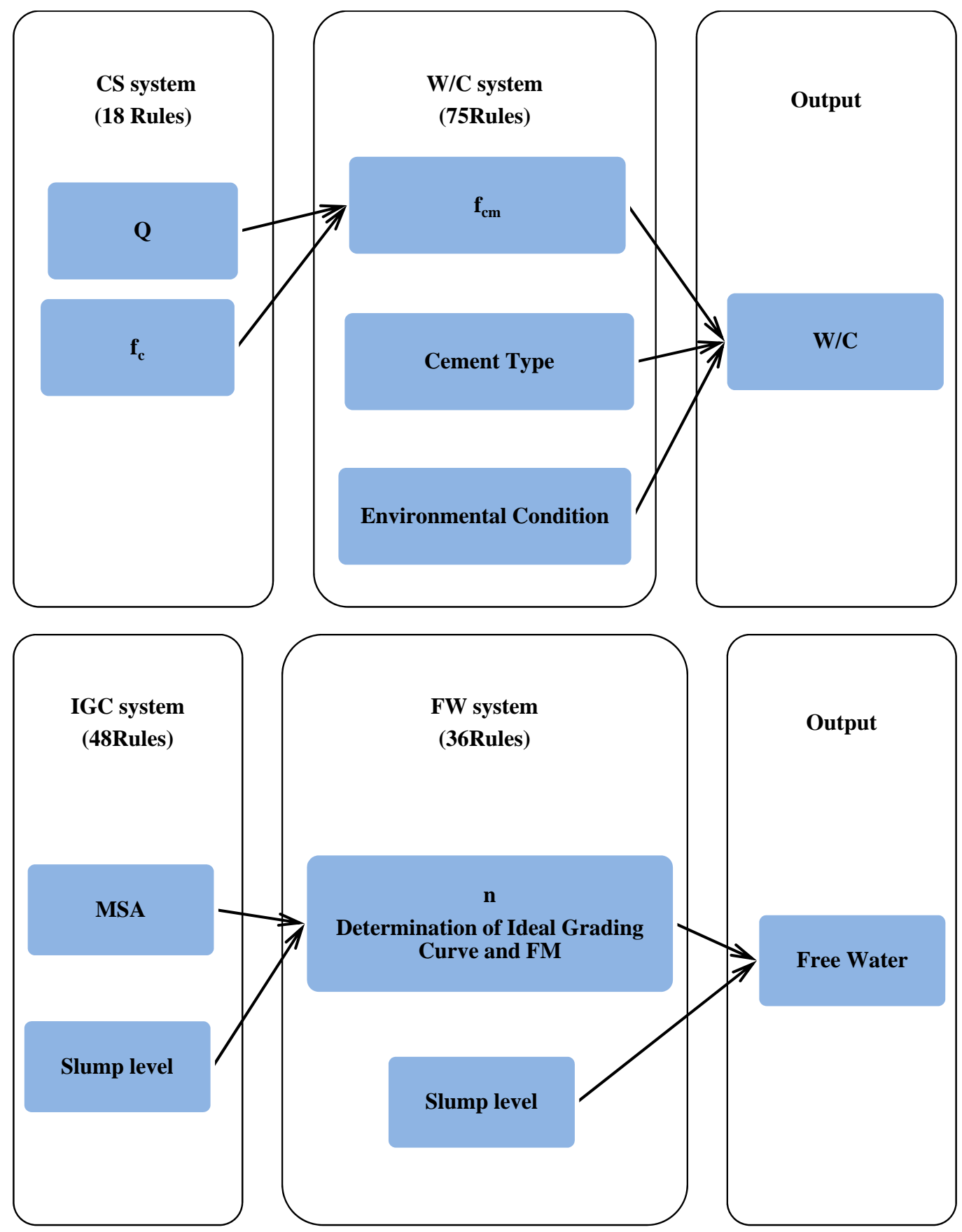

Fig. 1. Schematic Representation of Fuzzy System for Arriving Concrete Mix Proportion

\subsection{Compressive Strength Sub-Fuzzy System (CS System)}

CS system (Compressive Strength Sub-Fuzzy System) quantifies the target compressive strength of concrete at the age of 28 days $\left(f_{c m}\right)$. This system uses two fuzzy variables as the target compressive strength of concrete. $Q$ is the quality of the concrete and $\mathrm{f}_{\mathrm{c}}$ is the compressive strength and yield on target compressive strength as output $\left(f_{c m}\right)$. The set defined for $Q$ is:

$$
Q=\{H Q, M Q, L Q\}
$$

Where $H Q, M Q$ and $L Q$ are high quality, moderate quality and low quality of concrete, respectively.
The fuzzy label $f c$ is the set:

$$
f_{c}=\{M 15, M 20, M 25, M 30, M 35, M 40\}
$$

For example, M20 label represents an approximate specific compressive strength of $20 \mathrm{MPa}$ at the age of 28 days. The output fuzzy label $\left(f_{c m}\right)$ is defined in the following set:

$$
f_{c m}=\{T 2 O, T 24, T 27, T 31, T 36, T 40, T 43, T 48, T 51\}
$$

The fuzzy inference system has 18 rules, all of which were achieved experience in concrete mix design. Membership functions for the input and output parameters for the CS system are shown in Fig. 2. The output of the CS system as $f_{c m}$ surface of the combined effects of $f_{c}$ and $Q$ are shown in Fig. 3. 


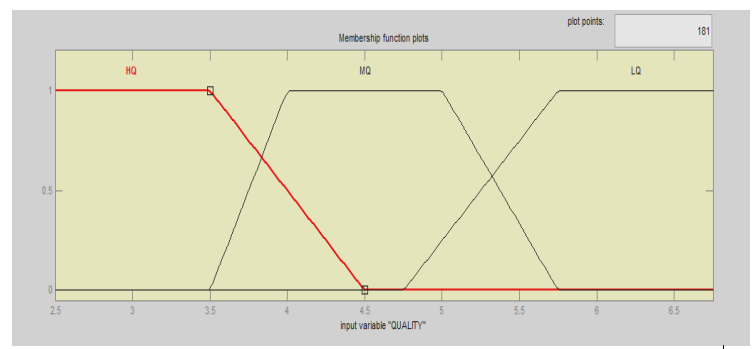

Input variable: Quality of concrete 18 Rules
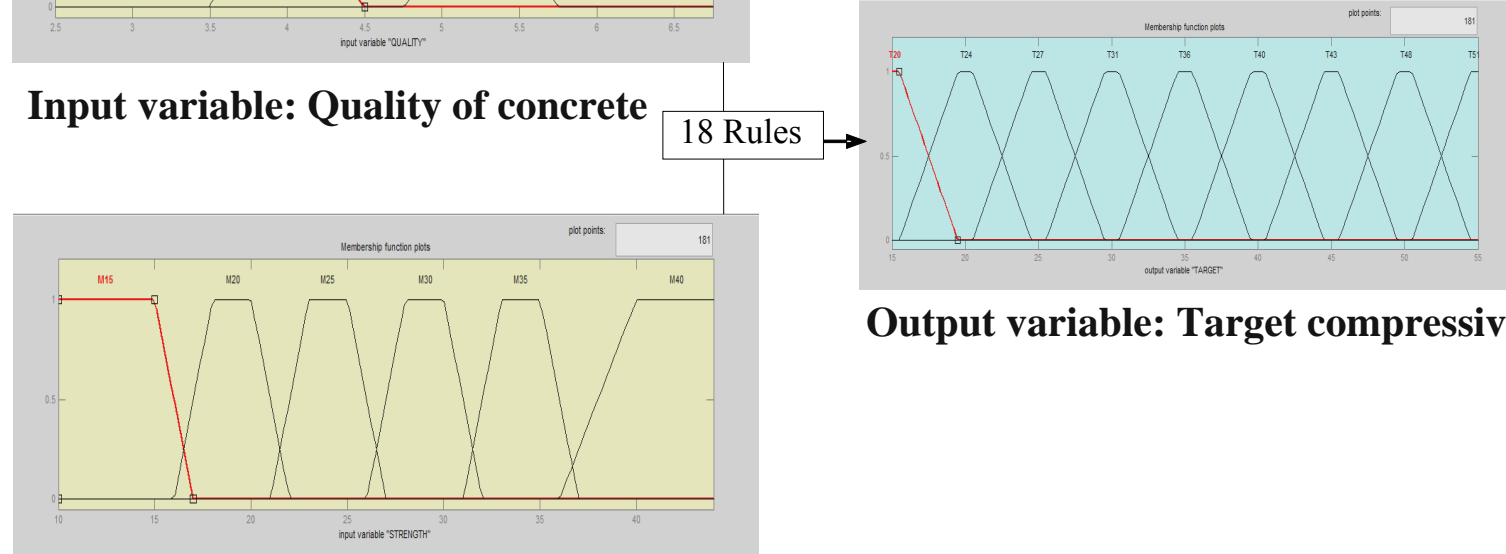

Input variable: Compressive strength

Output variable: Target compressive strength

Fig. 2. Fuzzy System to Determine Compressive Strength

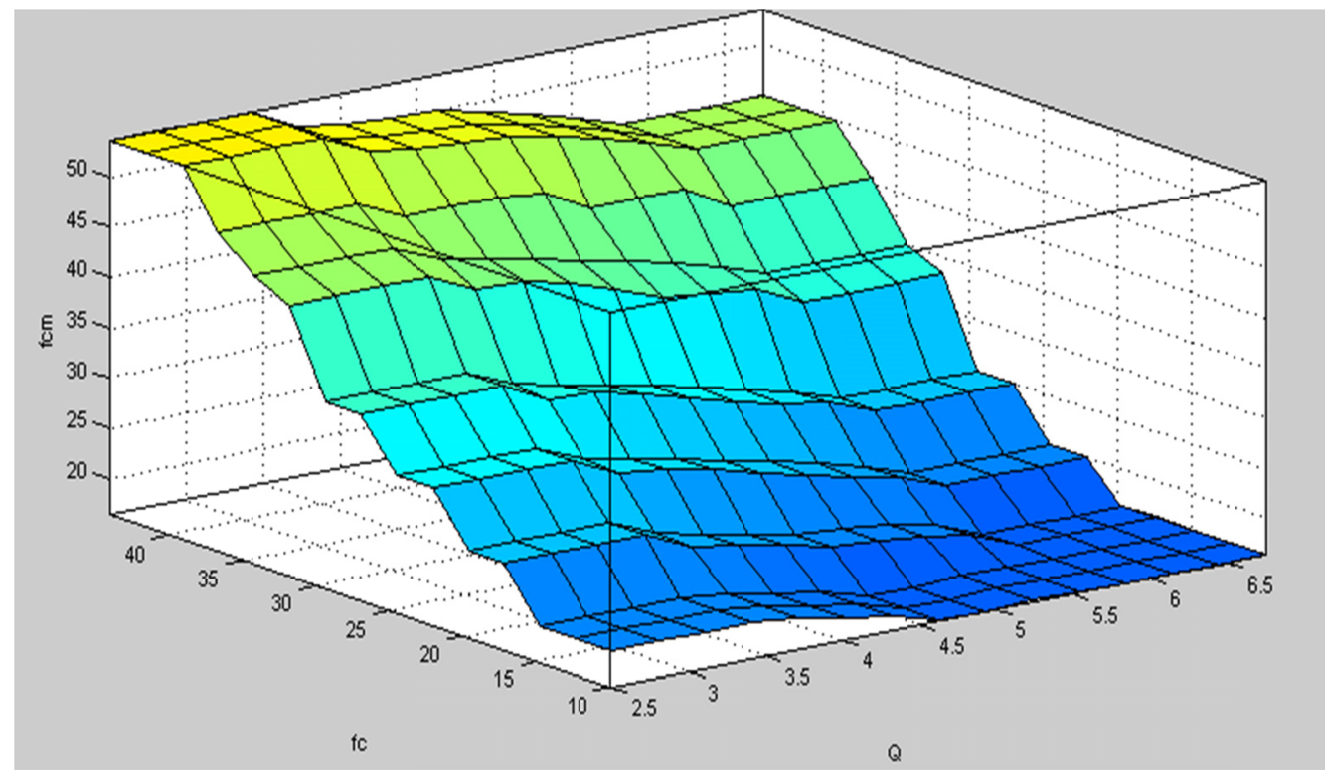

Fig. 3. Output of CS system: $f_{c m}$ surface due to combined effects $f_{c}$ and $S_{Q}$

\subsection{Water/Cement Ratio Sub-Fuzzy System (W/C System)}

This system uses three linguistic inputs with output waterto-cement ratio of required grade of concrete. The first input is $f_{c m}$, which is obtained from $C S$ system the second input is cement type with fuzzy label:

$$
\text { Cement type }=\{C 43, \text { C53 }\}
$$

Where $C 43$ and $C 53$ have cement mortar strength of 43 and $53 \mathrm{~kg} / \mathrm{cm}^{2}$ at 28 days. The third input is environmental conditions and their fuzzy labels set are:
Environmental condition $=\{M i, M o$, Se, VSe, Ex $\}$

Where $\mathrm{Mi}, \mathrm{Mo}$, Se, VSe and Ex are mild, moderate, severe, very severe and extreme environmental conditions respectively. The fuzzy inference system is given 75 rules. The output fuzzy label set of the systems are:

$$
W / C=\{0.40,0.41
$$$$
.0 .54,0.55\}
$$

For example 0.40 of $W / C$ represents that the water to cement ratio is 0.40.Membership functions for the input and output parameters for the $W / C$ system are shown in Fig. 4. The output of the $W / C$ system as $W / C$ surface of the combined inputs is shown in Fig. 5 as a 3D surfaces. 


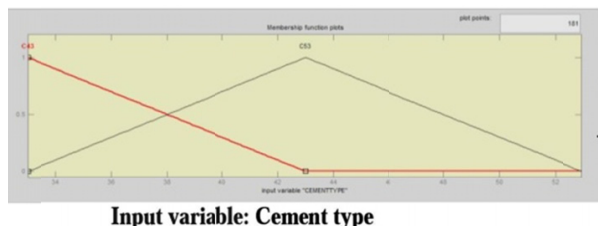

Input variable: Cement type
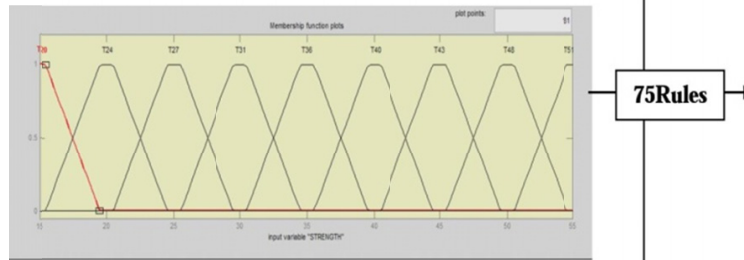

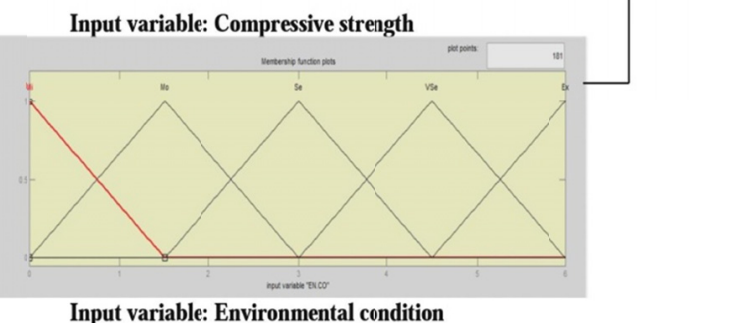

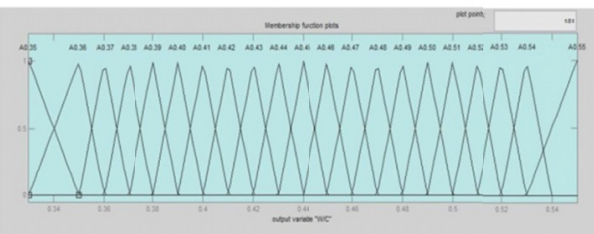

Output: water to cement ratio

Input variable: Environmental condition

Fig. 4. Input and output variables of $W / C$ system to determine the water to cement ratio

a)

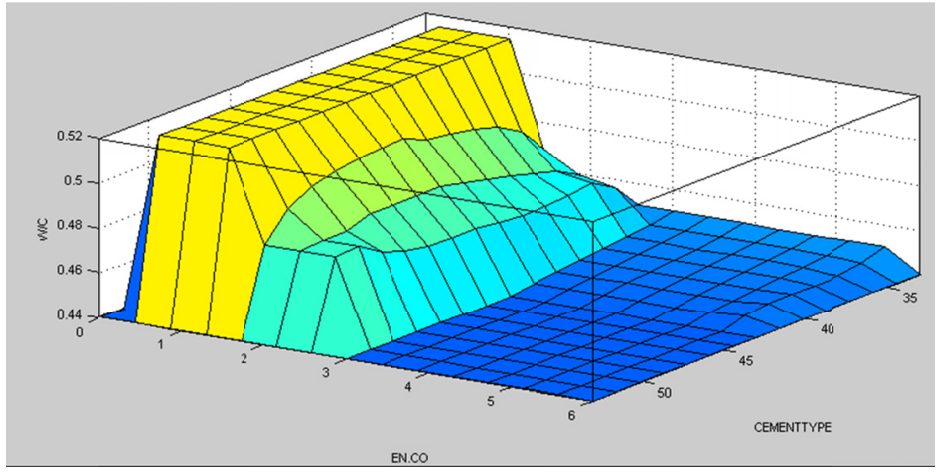

b)

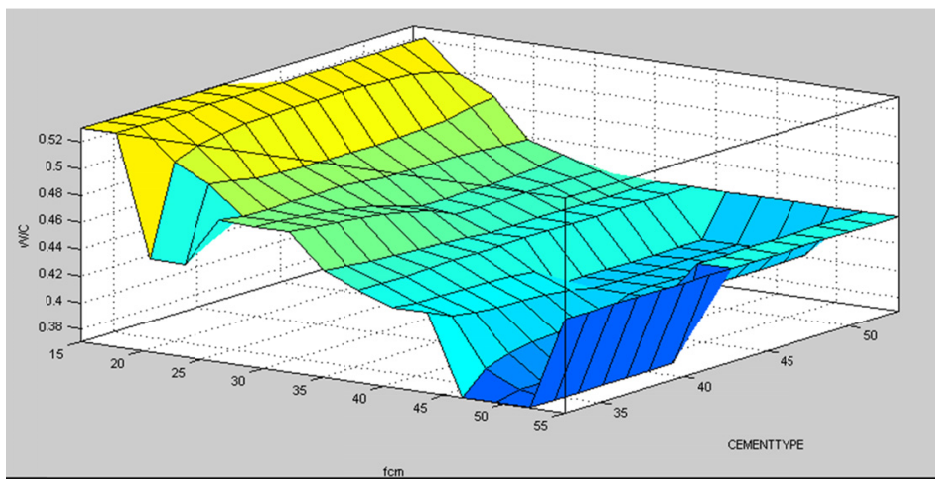

c)

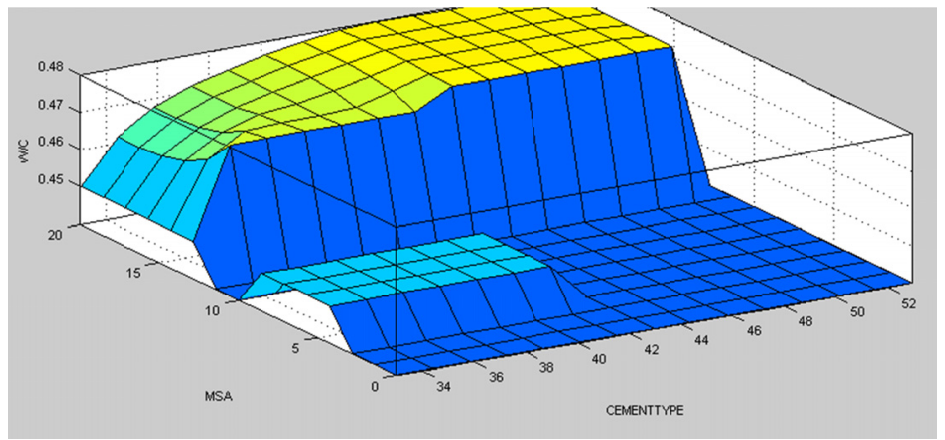

Fig. 5. Output of $W / C$ system for combined effect of: a) environmental condition and cement type on $W / C$; b) $f_{c m}$ and cement type on $W / C$; c) MSA and cement type on $W / C$ 


\subsection{Ideal Grading Curve Sub-Fuzzy System (IGC System)}

The aggregate grading curve should be modified and an optimized ratio of fine aggregate to coarse aggregate is chosen for maximum packing density. The ideal grading curve can be arrived by using the modified Fuller-Thompson relationship by defining power parameter $n$ as:

$$
P=\left[100 \% /\left(1-(0.075 / D)^{n}\right)\right] \times\left[(d / D)^{n}-(0.075 / D)^{n}\right]
$$

Where $P$ is the cumulative passing percentage from a sieve, $d$ is the sieve size and $D$ is the maximum size of aggregate (MSA). Parameter $n$ specifies the properties of ideal aggregate grading to maximize packing density. The input and output variables are to be trained in sub fuzzy system and they are defined as

$$
\begin{aligned}
& M S A=\{M S A 4.75, \text { MSA10, MSA12.5, MSA20 }\} \\
& \text { Slump level }=\{\text { Very Low, Low, Medium, High }\}
\end{aligned}
$$

Slump level is followed by using IS 456:2000 provisions. Where very low, low, medium and high are slump values of $>25 \mathrm{~mm}, 25 \mathrm{~mm}-75 \mathrm{~mm}, 50 \mathrm{~mm}-100 \mathrm{~mm}$ and $100 \mathrm{~mm}-150 \mathrm{~mm}$ respectively.

$$
\begin{gathered}
n=\{n 0.1, n 0.15, n 0.2, n 0.25, n 0.3, n 0.35, n 0.4, \\
n 0.45, n 0.5, n 0.55, n 0.6, n 0.67\}
\end{gathered}
$$

For example, $n 0.25$ means that the power of $n$ equals 0.25 . There are 48 defined rules. Fig. 6 shows the combined effects of slump and maximum size of aggregate on selection of $n$. After developing the value of $n$ as the output of IGC sub-fuzzy system, it is used in the Fuller-Thompson relationship (Eq. 8) to develop an ideal grading curve. Fig. 7 is an example of such a curve for $M S A=20 \mathrm{~mm}(M S A 20)$ and $n=0.427$. The output of $I G C$ system due to combined effect of maximum size of aggregate and slump value is shown in Fig. 8.
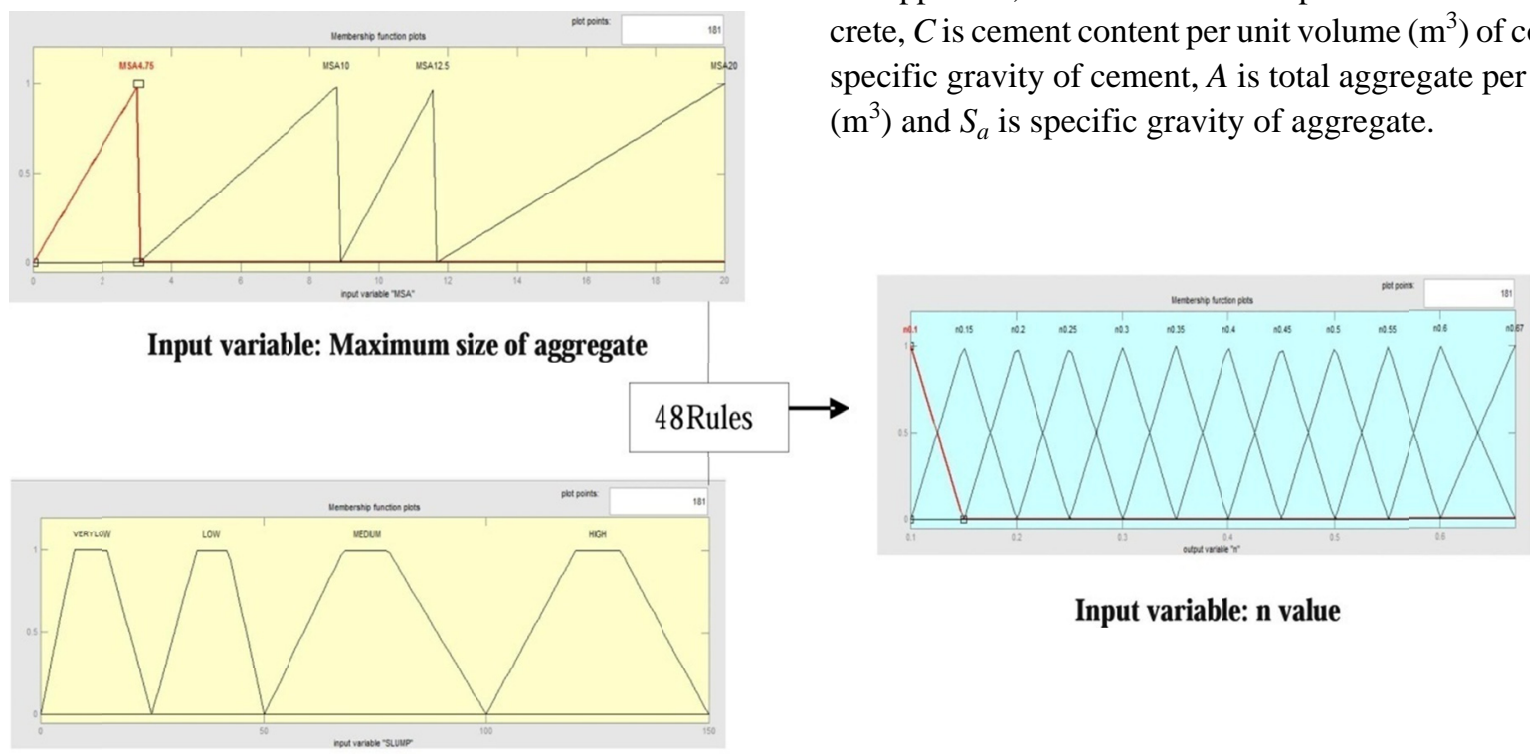

Input variable: $\mathrm{n}$ value

\subsection{Free Water Sub-Fuzzy System (FW System)}

FW system determines the available free water of concrete. It has two linguistic input variables with output free water. The first input, fineness modulus $(F M)$ is obtained from IGC system and second input is target slump value. The fuzzy label set for FM is:

$$
\begin{aligned}
F M= & \{F M 3, \text { FM3.5, FM4, FM4.5, FM5, } \\
& F M 5.5, F M 6, \text { FM6.5, FM7 }\}
\end{aligned}
$$

For example FM 4.5 means, the fineness modulus of aggregate is 4.5 . The second input, slump value is obtained from Eq. 9. 36 rules are given as input for the fuzzy inference. The outputs of the fuzzy system are:

$$
\begin{gathered}
\text { Free water }=\{150,160,170,180 \ldots \\
\ldots 230,240,250\}
\end{gathered}
$$

For example 150 in the Eq. 12 represents the free water content per unit volume is 150 . Membership functions for the input and output parameters for the $F W$ system are shown in Fig. 9. The output of the $F W$ system due to the combined effects of slump level and fineness modulus is shown in Fig. 10.

The cement content per unit volume of concrete can be calculated by using water to cement ratio obtained from W/C SYSTEM and free water content per unit volume from FW SYSTEM.

$$
\begin{gathered}
\text { Cement content per unit volume }=\text { Free water } \\
\text { per unit volume / (Water to cement ratio) }
\end{gathered}
$$

With the quantities of free water content and cement content obtained from Eq. 13, the total aggregate content per unit volume of concrete can be calculated from the following equation.

$$
V=\left[W+\left(C / S_{C}\right)+\left(A / S_{a}\right)\right][1 / 1000]
$$

Where, $V$ is volume of fresh concrete $\left(\mathrm{m}^{3}\right)$ minus volume of entrapped air, $W$ is water content per unit volume $\left(\mathrm{m}^{3}\right)$ of concrete, $C$ is cement content per unit volume $\left(\mathrm{m}^{3}\right)$ of concrete, $S_{C}$ is specific gravity of cement, $A$ is total aggregate per unit volume $\left(\mathrm{m}^{3}\right)$ and $S_{a}$ is specific gravity of aggregate.

\section{Input variable: Slump range}

Fig. 6. Fuzzy system to determine $n$ value 

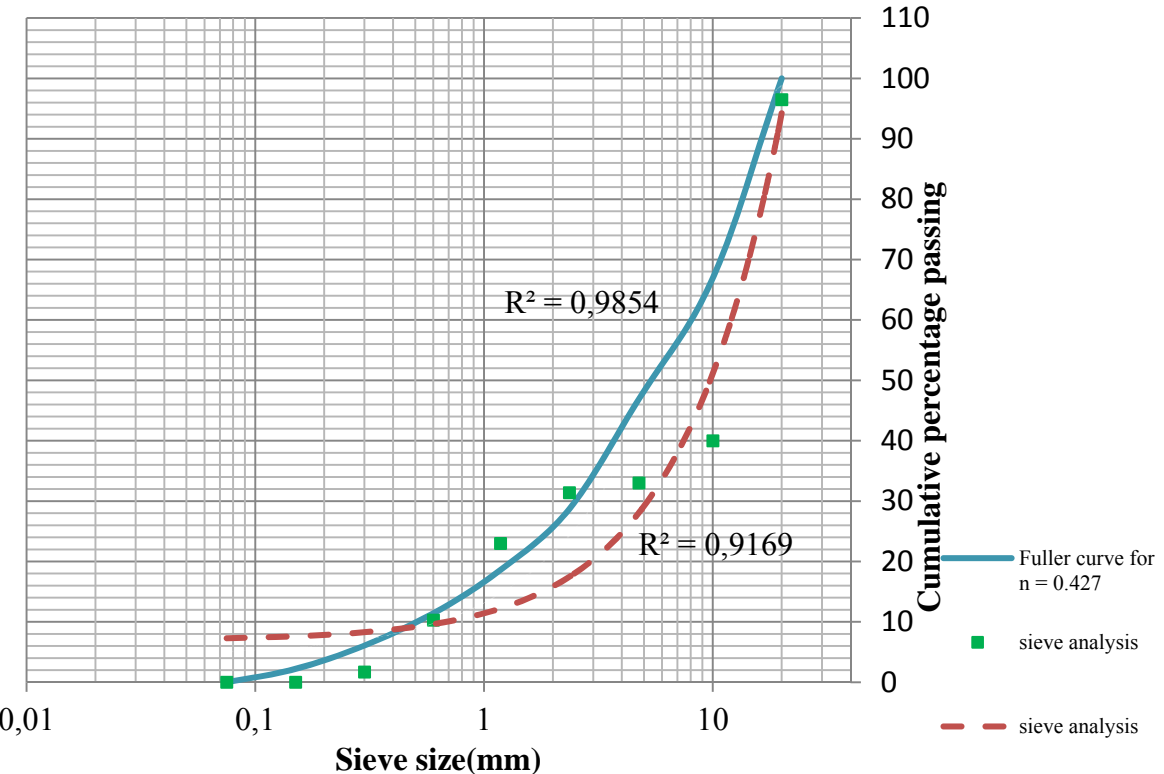

Fig. 7. Ideal grading curve

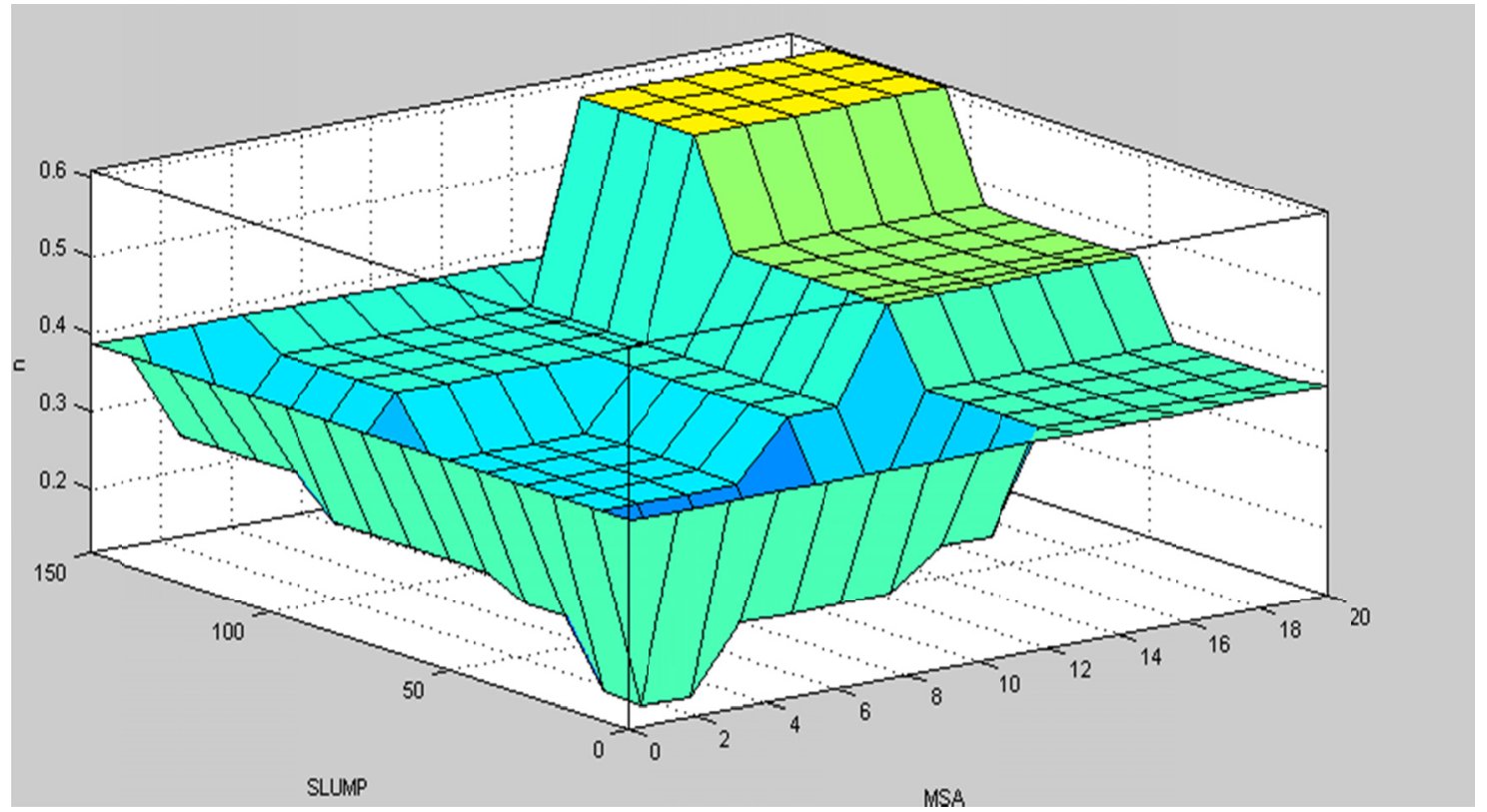

Fig. 8. Combined effects of slump and size of aggregate on selection of $n$

\section{Results and discussion}

\subsection{Material properties}

From the mechanical tests of coarse aggregate for concrete, it is clearly seen that the steel slag aggregates outperform the natural aggregates. The steel slag aggregate can be referred as a coarse aggregate suitable for concrete.

\subsection{Ideal Grading Curve}

The cumulative percentage passing in each sieve as per proposed ideal grading curve and for aggregates used in M30 concrete as per IS method are calculated by using the curves shown in Fig. 7 and are shown in Table 6. The continuous particle size distribution enables higher packing density and improves the concrete properties.

\subsection{Validation and Feasibility of Fuzzy System}

The feasibility of the proposed fuzzy system is evaluated by comparing the mix proportions and performance with that of conventional IS method for $0 \%, 10 \%, 20 \%, 30 \%, 40 \%, 50 \%$, $60 \%, 70 \%, 80 \%, 90 \%$ and $100 \%$ replacement by steel slag. The water cement ratio of fuzzy model is less which is reflected in the free water content. From Table 7, it can be observed 

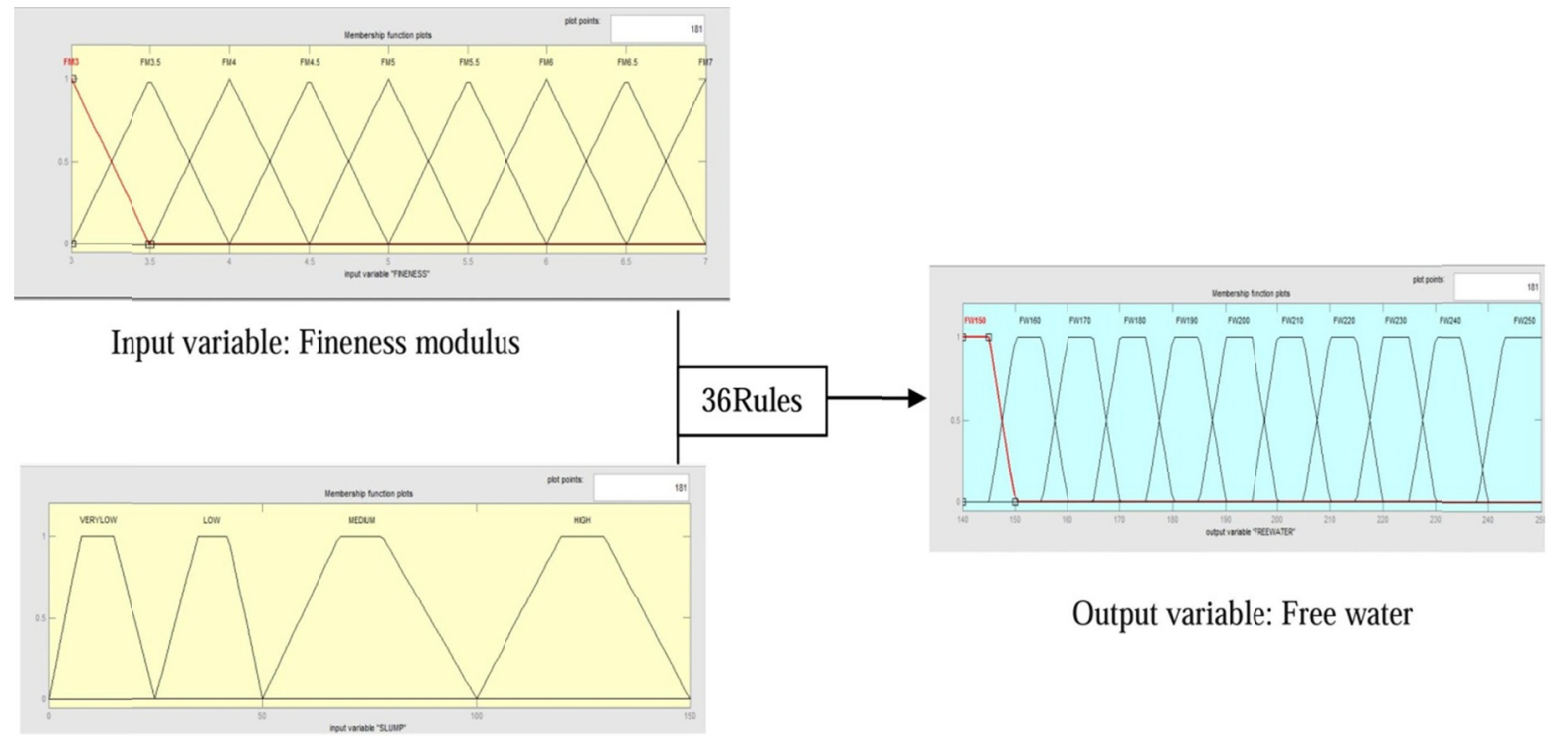

Input variable: Slump range

Fig. 9. Input and output parameters of FW system to determine free water content

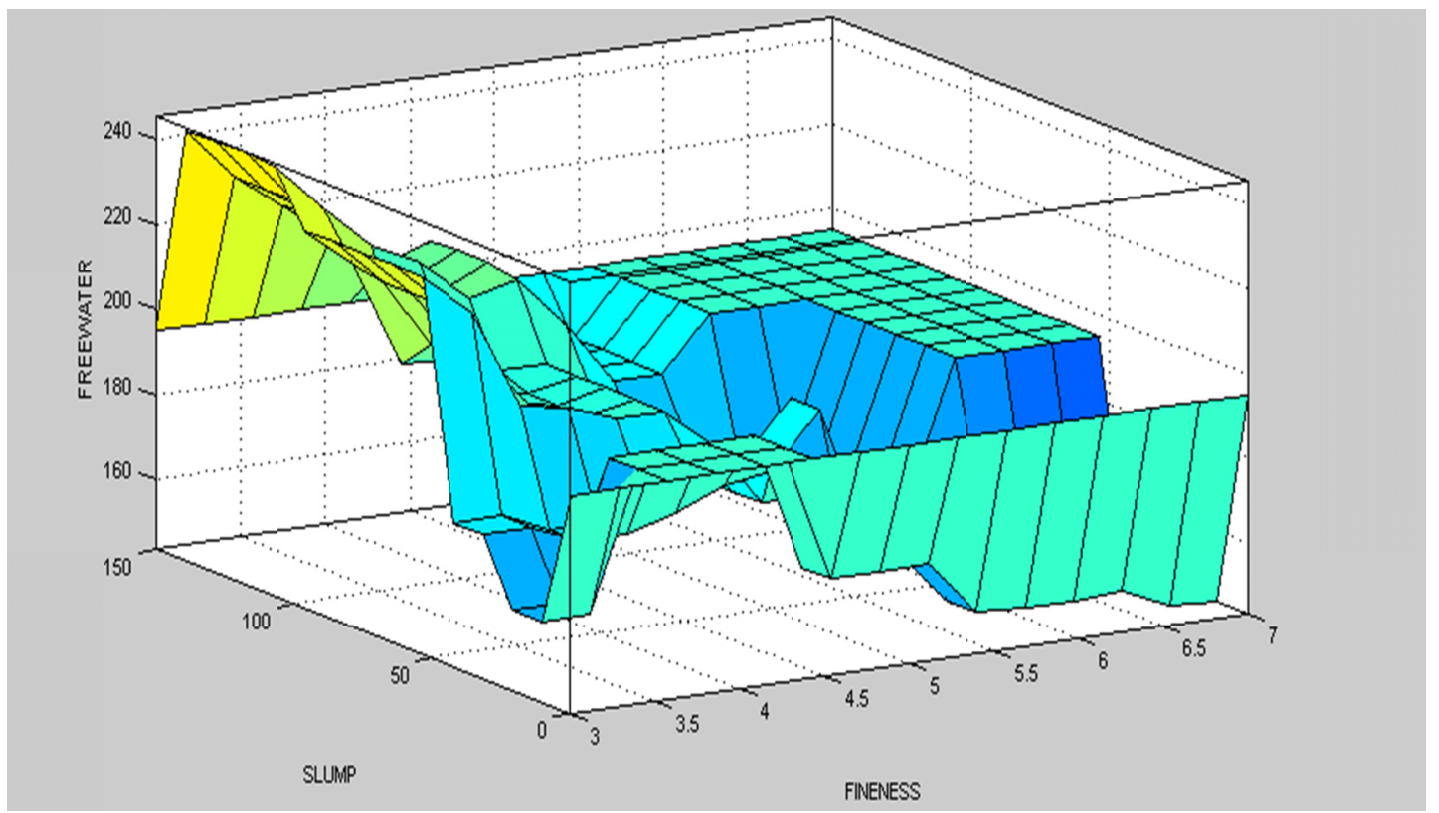

Fig. 10. Combined effects of slump and Fineness Modulus

TABLE 6 that for the same volume of concrete, the weight of cement,

Comparison of Weight Retained

\begin{tabular}{|c|c|c|}
\hline \multirow{2}{*}{$\begin{array}{c}\text { Sieve size } \\
(\mathbf{m m})\end{array}$} & \multicolumn{2}{|c|}{ Cumulative Percentage passing } \\
\cline { 2 - 3 } & $\begin{array}{c}\text { As per ideal } \\
\text { grading curve }\end{array}$ & $\begin{array}{c}\text { For aggregates used in } \mathbf{M 3 0} \\
\text { concrete as per IS method }\end{array}$ \\
\hline 20 & 100 & 96.5 \\
\hline 10 & 66.9 & 40 \\
\hline 4.75 & 46.9 & 33 \\
\hline 2.36 & 28.7 & 31.4 \\
\hline 1.18 & 18.6 & 23 \\
\hline 0.6 & 11.4 & 10.3 \\
\hline 0.3 & 6.1 & 1.7 \\
\hline 0.15 & 2.2 & 0 \\
\hline 0.075 & 0 & 0 \\
\hline $\mathrm{R}^{2}$ & 0.985 & 0.916 \\
\hline
\end{tabular}
higher than that of IS method. Therefore it can be concluded that the bulk density of Fuzzy model is greater than that of IS method.

Mix Design of Fuzzy Model versus IS Method

\begin{tabular}{|c|c|c|c|c|c|c|}
\hline $\begin{array}{l}\text { Percentage } \\
\text { replacement }\end{array}$ & As per & $\begin{array}{l}\text { W/C } \\
\text { ratio }\end{array}$ & $\begin{array}{l}\text { Cement } \\
\left(\mathrm{kg} / \mathrm{m}^{3}\right)\end{array}$ & \begin{tabular}{|c|} 
Coarse \\
aggregate \\
$\left(\mathrm{kg} / \mathrm{m}^{3}\right)$
\end{tabular} & \begin{tabular}{|c|} 
Fine \\
aggregate \\
$\left(\mathrm{kg} / \mathrm{m}^{3}\right)$
\end{tabular} & $\begin{array}{c}\text { Free } \\
\text { water } \\
\left(\mathrm{kg} / \mathrm{m}^{3}\right)\end{array}$ \\
\hline \multirow{2}{*}{$\begin{array}{c}0 \% \text { to } 100 \% \\
(10 \% \\
\text { increments })\end{array}$} & $\begin{array}{l}\text { Fuzzy } \\
\text { model }\end{array}$ & 0.44 & 4 & & 035.1 & 195 \\
\hline & IS & 0.45 & 438 & 1148.6 & 637.8 & 197 \\
\hline
\end{tabular}




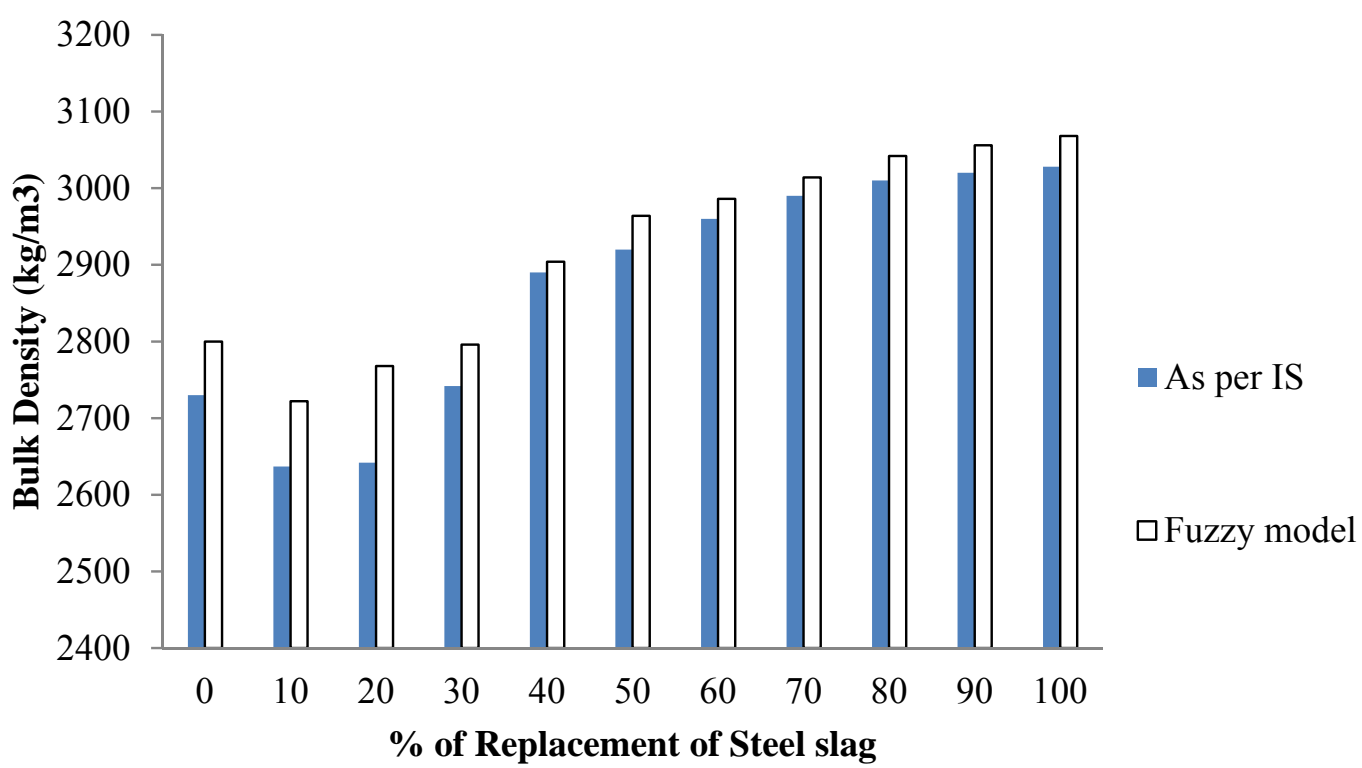

Fig. 11. Comparison of Bulk Density by IS as per method and Fuzzy model

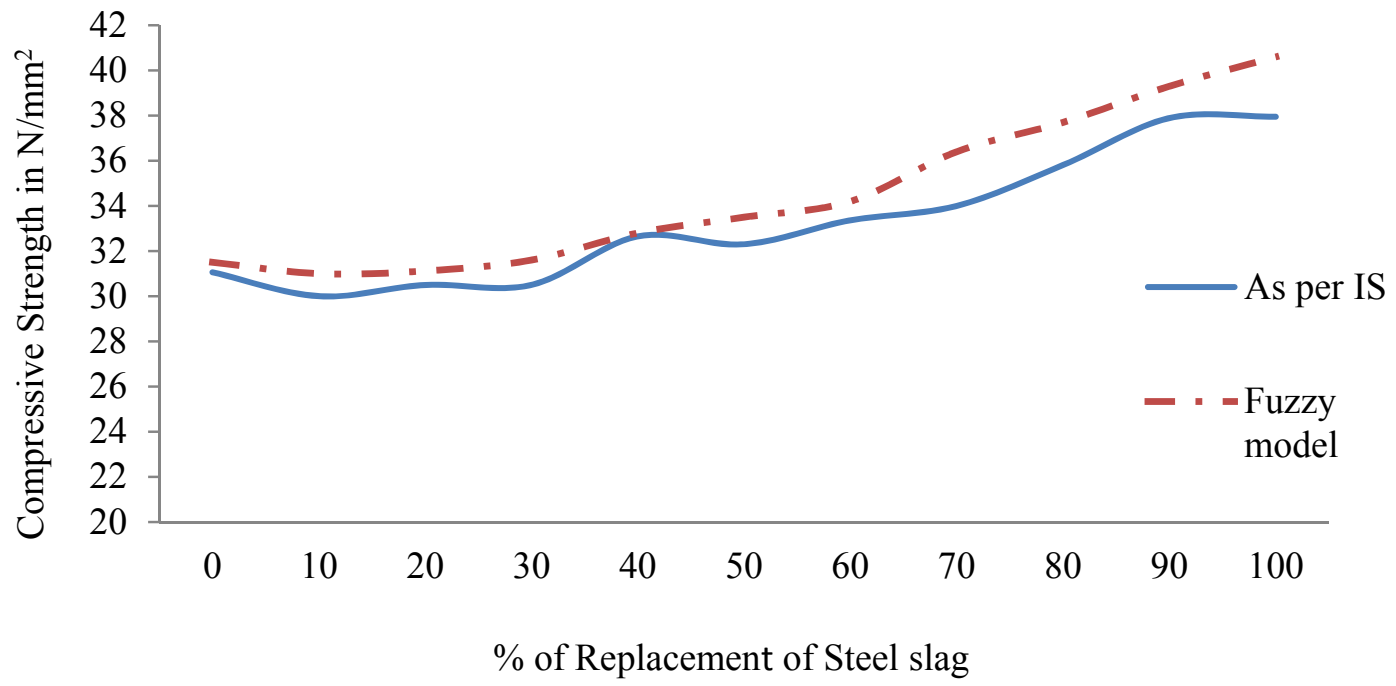

Fig. 12. Comparison of Compressive strength by IS method and Fuzzy model

The Fig. 11 and Fig. 12 show the compressive strength and bulk density of concrete cube as per proposed fuzzy model and IS method. Hardened concrete is tested for bulk density as per IS 1199 and Compressive Strength as per IS516:1959. The bulk density of fuzzy model shows considerable increase due to improved packing density of aggregates by following the Fuller Thomson curve. The compressive strength of Fuzzy model is higher than those of IS method due to high packing density. It is observed that, all percentage replacement levels show considerable increase in compressive strength and bulk density in Fuzzy model.

\section{Conclusions}

- $\quad$ The concrete mix proportion of the given fuzzy model agrees with IS method and its comparatively better.
- As a result of developing ideal grading curve in fuzzy model, the proposed fuzzy model has increased compressive strength than IS method.

- A comparison of results from the proposed fuzzy model with those from the IS method indicates increased bulk density which is understandable from $3 \%$ increase in bulk density of fuzzy model than that of IS method in $0 \%$ replacement.

- In both proposed fuzzy system and IS method, there is a remarkable increase in compressive strength and bulk density, with increment in the percentage replacement of steel slag.

- $\quad$ From the increased compressive strength for $100 \%$ replacement by steel slag, it can be concluded that that steel is better alternate material for natural coarse aggregate. 


\section{Acknowledgement}

The authors express their deep gratitude to JSW Salem Steel Work, Tamilnadu, India for their cooperation to develop the research paper.

\section{REFERENCES}

[1] T. Sowmiya, Application of Optical Basicity Parameter to foamings of Slags, Central Pollution Control Board (2004).

[2] Y. Kirillidi: Electric Arc Furnace Slag Utilisation, Proceedings of the 9th International Conference on Environmental Science and Technology (2005).

[3] P. Jigar, Patel Cleveland State University, (2006).

[4] M. Nadeem, Experimental Investigation Of Using Slag as an alternative to normal Aggregates (coarse and fine) in Concrete, International Journal of Civil and Structural Engineering 3 (2012).

[5] I. Netinger, Concrete containing Steel Slag Aggregate Performance After High Temperature Exposure, Concrete Repair, Rehabilitation and Retrofi tting III, Alexander et al. (eds) Taylor \& Francis Group, London (2012), ISBN 978-0-415-89952-9.

[6] K.G. Hiraskar, Use Of Blast Furnace Slag Aggregate in Concrete, International Journal Of Scientific \& Engineering Research 4, 5, May (2013).

[7] Dr.K. Chinnaraj, Study on Concrete using Steel Slag as Coarse Aggregate Replacement and Ecosand as Fine Aggregate Replacement, IJREAT International Journal of Research in Engineering \& Advanced Technology 1 (2013)

[8] Sultan A. Tarawneh, Effect of using Steel Slag Aggregate on Mechanical Properties of Concrete, American Journal of Applied Sciences 11 (5), 700-706 (2014).

[9] Khalid Raza, Strength Analysis of Concrete by using Iron Slag as a Partial Replacement of Normal Aggregate (Coarse) in Concrete, IJSR 3, 10 (2014),

[10] Parvizghoddousi Ali Akbar ShirzadiJavid, JafarSobhani, A Fuzzy System Methodology for Concrete Mixture Design Considering Maximum Packing Density and Minimum Cement Content, Arabian Journal Science Engineering 40, 2239-2249 (2015).
[11] Thomas H. Bleeck, Particle Packing; An Effective Approach to Optimized Design of Ultra High Strength and Self Compacting Concrete, Engineering Project and Practical Experience (2011).

[12] A.M Nevillie, Properties of Concrete. Longman House (1995).

[13] IS: 2386 ( Part I) - 1963, Indian Standard, Methods of tests for aggregate for concrete, Bureau of Indian Standards, New Delhi (1963).

[14] IS 516:1959, Methods of test for strength of concrete, Bureau of Indian Standards, New Delhi (1959).

[15] M. Arivoli, Characterisation of EOF Steel Slag as Coarse Aggregate in Concrete, Integrated Journal of Engineering Research and Technology 216, 244-249 (2015).

[16] A.A.M. Sonja, Using particle packing technology for sustainable concrete mixture design, HERON 57, 22012.

[17] G. Jeenu, P. Vinod, LaluMangal, Packing characteristics of aggregates for High Performance Concrete, International journal of earth science and engineering 05, 1424-1431 (2012).

[18] R. Malathy, Study on Optimum Replacement of EOF steel slag as fine Aggregate in M20 concrete, IJERT-216\&116-121(2015).

[19] R. Malathy, Determination of Mechanical Properties of EOF Steel Slag Replaced Concrete Using NDT, International journal of Earth sciences and Engineering (2015).

[20] R. Malathy, Study On Mechanical Properties of Concrete Replacing Eof Steel Slag as Fine Aggregate, International Journal of Applied Engineering Research (2015).

[21] IS: 383-1970: Specification for Coarse and Fine Aggregates from Natural Sources for Concrete, Bureau of Indian Standard, And New Delhi (197).

[22] IS: 10262-2009 (Reaffirmed 2004): Recommended guidelines for concrete mix design, Bureau of Indian Standard, New Delhi (2004).

[23] M.S Shetty, Concrete Technology, S Chand Publications, (2005).

[24] ASTM C123/C123-14, Standard Test Method for Lightweight Particles in Aggregate, Standards ASTM International, (2014).

[25] IS: 8112:1989, Specification for 43 Grade OPC, Bureau of Indian Standard, reaffirmed 1997, New Delhi (1997). 